\title{
Influence of electroacupuncture on the points BP6 and E36 regarding gastric motility in Wistar rats
}

\section{Influência da eletroacupuntura nos pontos BP6 e E36 na motilidade gástrica de ratos Wistar}

\author{
Taiane Rita Carnevali ${ }^{1 *}$; Fábio da Silva e Silva²; Luiz Filipe Dame Schuch ${ }^{3}$; \\ Marina de Mattos Ferrasso ${ }^{4}$; Luiz Paiva Carapeto ${ }^{5}$; \\ Guilherme Albuquerque de Oliveira Cavalcanti ${ }^{5}$; Marlete Brum Cleff ${ }^{6}$
}

\begin{abstract}
The study aimed to evaluate by radiographic examination the action of electroacupuncture on gastric motility in experimental animals. We used 24 Wistar rats, three months old, that received five metallic spheres, via orogastric tube (OT), with $2 \mathrm{~mL}$ of barium contrast, followed by treatments: electroacupuncture points E36 and BP6 (T1); electroacupuncture in stitches (T2); sterile distilled water OT (T3); metoclopramide OT (T4). After treatment, serial radiographs, hourly, were made to follow the gastric emptying time of the spheres in rats. By analyzing the time of exit of the first sphere, animals in the group T1 had an average of 3h30min; at T2 the average was higher 6 hours; in T3 was $5 \mathrm{~h} 18 \mathrm{~min}$, and T4 showed an average of $4 \mathrm{~h} 36 \mathrm{~min}$. The action of electroacupuncture was comparable to the action of metoclopramide, which is know to increase peristalsis, whereas the response of the Shan group (T2) was close to the negative control group. Considering the results it was concluded that electroacupuncture at points predetermined significantly increases gastric peristalsis, reducing gastric emptying time in rats, may be an option for the treatment of motility disorders.
\end{abstract}

Key words: Radiography. Gastrointestinal. Rats. Acupuncture.

\section{Resumo}

O estudo objetivou avaliar através de exame radiográfico, a ação da eletroacupuntura na motilidade gástrica de animais experimentais. Foram utilizados 24 ratos Wistar, três meses de idade, que receberam cinco esferas metálicas via sonda orogástrica (SO) com $2 \mathrm{~mL}$ de contraste baritado, seguido dos tratamentos: eletroacupuntura nos pontos BP6 e E36 (T1); eletroacupuntura em pontos falsos (T2); água destilada estéril SO (T3); metoclopramida SO (T4). Após os tratamentos, foram feitas radiografias seriadas, de hora em hora, para acompanhar o tempo de esvaziamento gástrico das esferas nos ratos. Ao analisar o momento de saída das primeiras esferas, os animais do grupo T1 apresentaram uma média

\footnotetext{
${ }^{1}$ Médica Veterinária, Hospital Veterinário da Universidade de Passo Fundo, UPF, Passo Fundo, RS, Brasil. E-mail: taianecarnevali@ yahoo.com.br

2 Médico Veterinário, Hospital Veterinário da Faculdade de Veterinária, Universidade Federal de Pelotas, UFPel, Pelotas, RS, Brasil. E-mail: silvamedvet@hotmail.com

3 Prof. Associado, Departamento de Veterinária Preventiva, UFPel, Pelotas, RS, Brasil. E-mail: bitoxu@ig.com.br

${ }^{4}$ Discente, Programa de Pós-Graduação em Medicina Veterinária da Universidade Estadual Paulista, UNESP, Botucatu, SP, Brasil. E-mail: marinaferrasso@gmail.com

${ }_{5}^{5}$ Profs. Adjuntos, Departamento de Clínicas Veterinária, UFPel, Pelotas, RS, Brasil. E-mail: luizcarapeto@gmail.com; guilherme@ufpel.edu.br

${ }^{6}$ Prof. Associado do Departamento de Clínicas Veterinária, UFPel, Pelotas, RS, Brasil. E-mail: emebrum@bol.com.br

* Author for correspondence
} 
de 3h30min; no T2 a média foi maior que $6 \mathrm{~h}$, no T3 foi de $5 \mathrm{~h} 18 \mathrm{~min}$ e no T4 de $4 \mathrm{~h} 36 \mathrm{~min}$. A ação da eletroacupuntura foi comparável à ação da metoclopramida, que sabidamente aumenta o peristaltismo, enquanto que a resposta do grupo Shan (T2) aproximou-se do grupo controle negativo. Diante dos resultados conclui-se que a eletroacupuntura nos pontos pré-determinados aumenta significativamente o peristaltismo gástrico, diminuindo assim o tempo de esvaziamento gástrico em ratos, podendo ser uma opção para o tratamento de distúrbios da motilidade.

Palavras-chave: Radiografia. Gastrointestinal. Ratos. Acupuntura.

Gastric disorders are common within clinical medicine of small animals. A variety of factors interfere with the functionality of the gastrointestinal tract, such as infectious agents and morphological, neurological and metabolic abnormalities (DRAEHMPAEHL; ZOHMANN, 1997; JOAQUIM et al., 2008). Treatment plans for abnormalities of the gastrointestinal tract consist of the most specific therapy possible for the alterations, including use of drugs such as pro-kinetics, antiemetics, mucosa protectors and $\mathrm{H} 1$ antagonists, among others. However, these present adverse effects such as restlessness, anxiety, diarrhea, flatulence and asthenia, among others (DRAEHMPAEHL; ZOHMANN, 1997; TAKAHASHI, 2006).

Acupuncture has been used to treat gastrointestinal disorders in human medicine for thousands of years in China (TAKAHASHI, 2006) and has now been disseminated worldwide (BALESTRINI et al., 2005). However, modifications to the original technique have been made, such as electroacupuncture, which consists of application of doses of electrical impulses at acupuncture therapeutic points (acupoints) through using electrical pens or electrodes (DRAEHMPAEHL; ZOHMANN, 1997). Studies have indicated that use of acupuncture may promote stimulation or inhibition of the enteric nervous system (BALESTRINI et al., 2005), thereby altering motility, gastric secretion (BALESTRINI et al., 2005; TAKAHASHI, 2006), electrical activity, gastric $\mathrm{pH}$ and gastrointestinal cytoprotection (DRAEHMPAEHL; ZOHMANN, 1997). Nonetheless, the mechanisms of action have still not been fully elucidated and, within veterinary medicine, studies are still only just beginning (TAKAHASHI, 2006).
Given the interest in using acupuncture within veterinary medicine, and the increasing search for complementary and less invasive therapies, the present study had the aim of evaluating the action of electroacupuncture on gastric motility, in an experimental model, by means of radiographic examination.

Twenty-four three-month-old female albino Wistar rats of mean weight $350 \mathrm{~g}$ were used. These were divided into four groups and were kept in the central vivarium of the Federal University of Pelotas (UFPel) under conditions of light/dark cycles of 12 hours each, controlled temperature $\left( \pm 23^{\circ} \mathrm{C}\right)$, water ad libitum and commercial feed provided according to weight. The present experiment was approved by the Ethics Committee for Animal Experimentation of UFPel (protocol no. 6538/2010).

Over a two-week period before the evaluation, the animals were adapted to the handing required for administration of the treatments and for performing radiographic examinations. After this period, they were given identifications and were weighed. They were subjected to fasting for 16 hours and received five metal spheres of $1 \mathrm{~mm}$ in diameter by means of an orogastric probe, together with $2 \mathrm{~mL}$ of $10 \%$ barite contrast. All the rats were anesthetized using an association of ketamine (30 $\mathrm{mg} / \mathrm{kg} / \mathrm{IM})$ and xylazine ( $3 \mathrm{mg} / \mathrm{kg} / \mathrm{IM}), 30$ minutes before introducing the probe. They then received the following treatments:

Group T1 (acupuncture points) $(\mathrm{n}=6)$ : electroacupuncture at a frequency of $2 \mathrm{~Hz}$ for 20 minutes at the points BP6 and E36; group T2 (sham points) $(n=6)$ : electroacupuncture at a frequency 
of $2 \mathrm{~Hz}$ for 20 minutes at two false points located on the skin of the lateral face of the femur, one in the proximal portion and the other in the distal portion; group T3 (negative control) $(\mathrm{n}=6)$ : 0.1 $\mathrm{mL}$ of sterile distilled water, IM, $30 \mathrm{~min}$ before the probing; and group T4 (positive control) $(n=6): 2$ $\mathrm{mg} / \mathrm{kg}$ of metoclopramide, IM, $30 \mathrm{~min}$ before the orogastric probing. Groups T1 and T2 received an injection of $0.1 \mathrm{~mL}$ of sterile distilled water, IM, 30 min before the probing.

As recommended in the specialized literature (TATEWAKI et al., 2003; SUGAI et al., 2004), stomach emptying was evaluated by means of eight radiographs on each animal, performed at the times of $0,1,2,3,4,5,6$ and 24 hours after the orogastric probing.

The statistical analysis was performed by means of analysis of variance (ANOVA) with the least significant difference (LSD) test, taking $\mathrm{p}<0.05$.

From analyzing the time at which the first of the spheres exited the stomachs of the rats in the different treatment groups, it was observed that the animals in group T1 presented a mean of $3 \mathrm{~h} 30$ min; in group T2 the mean was greater than $6 \mathrm{~h}$; in group T3 the mean was $5 \mathrm{~h} 18 \mathrm{~min}$; and in group T4 the mean was $4 \mathrm{~h} 36 \mathrm{~min}$.
Regarding the time at which the spheres exited in the different treatments, it was observed that use of electroacupuncture (T1) increased peristalsis and thus decreased the time to three hours. This was statistically different in relation to the sham point treatment (T2) and the negative control (T3) $(\mathrm{p}<$ 0.05 (Figure 1).

Regarding the percentage of the number of spheres used per treatment $(n=30)$ that passed through the stomach within the first six hours, $40 \%$ of them passed through in $\mathrm{T} 1,13.33 \%$ in $\mathrm{T} 2$, $13.33 \%$ in $\mathrm{T} 3$ and $26.66 \%$ in $\mathrm{T} 4$.

Over the 24 hours of the experiment, it was observed that in groups $\mathrm{T} 1, \mathrm{~T} 2$ and $\mathrm{T} 4$, respectively $93.3 \%, 86.6 \%$ and $90 \%$ of the spheres were eliminated, while in group T3 the percentage of the spheres eliminated from the gastrointestinal tract was $43.3 \%$. Thus, the stomach emptying time among the animals in this group was greater, but there was no statistical difference between the treatments.

In a general analysis on the results, it was observed that stimulation of the points BP6 and E36, by means of electroacupuncture, resulted in faster elimination of the spheres from the stomach and also a larger quantity of spheres eliminated. The groups were statistically different, thus: $\mathrm{T} 1^{\mathrm{A}}, \mathrm{T} 2^{\mathrm{BC}}$, $\mathrm{T} 3^{\mathrm{C}}$ and $\mathrm{T} 4^{\mathrm{AB}}$, and this is shown in Figure 1.

Figure 1. Elimination from the stomach of five spheres that had been administered orally to Wistar rats that underwent the following treatments: electroacupuncture (T1), sham points (T2), negative control (T3) and metoclopramide (T4).

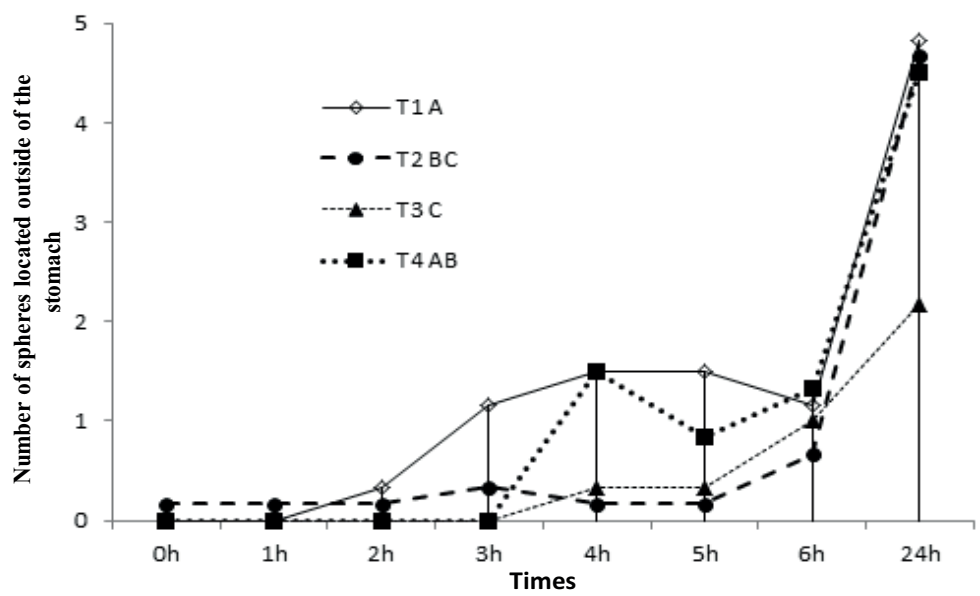

Different letters signify statistical differences with $\mathrm{p}<0.05$. 
Radiological evaluation of the motility of the gastrointestinal tract under the action of electroacupuncture through using metal spheres in association with barium sulfate had not previously been done, and the present study was novel in this regard. Some other authors had evaluated the motility of the gastrointestinal tract in experimental models subjected to electroacupuncture (OUYANG et al., 2002; TABOSA et al., 2004; SUGAI et al., 2004), by means of evaluation techniques such as use of activated carbon, plastic spheres (SUGAI et al., 2004; TABOSA et al., 2004) and a cannula introduced into the duodenum (OUYANG et al., 2002). Recognition of acupuncture as a specialty within veterinary medicine, along with the growing demand for complementary therapy for companion animals, has made it possible to use this technique within current veterinary clinical practice, integrated with the traditional treatment methods (DRAEHMPAEHL; ZOHMANN, 1997).

The electroacupuncture frequency used in this study was $2 \mathrm{~Hz}$, for $20 \mathrm{~min}$, and was applied to the points BP6 and E36 (TABOSA et al., 2004). According to the literature, the action of electroacupuncture is influenced by the frequency and amplitude of the stimulation, such that frequencies lower than $15 \mathrm{~Hz}$ and low amplitude lead to tonification of the points (DRAEHMPAEHL; ZOHMANN, 1997), which was thus concordant with the observations on the animals of group T1. Yin and Chen (2010) used electroacupuncture on the point E36 and demonstrated that there was an increase in stomach emptying, while Takahashi (2006) observed through stimulation of the point E36 that there was greater secretion of acid in the experimental animals. In human medicine, the Zusanli (E36) and Sanyinjiao (BP6) points are commonly used in treating gastrointestinal tract conditions such as constipation, diarrhea and vomiting, among others (BALESTRINI et al., 2005). In animals, these points have been cited as useful in situations of motor dysfunction and visceral pain and for controlling gastric secretions
(BALESTRINI et al., 2005). Furthermore, other points that have been described, such as PC6 (TAKAHASHI, 2006) and BL27 (CHOI, 2001), have been used with considerable success.

The acupoints used in the treatment $\mathrm{T} 1$ are located in the pelvic limbs and stimulation of these points results in increased gastric motility. This finding is concordant with those of other studies (TATEWAKI et al., 2003; TAKAHASHI, 2006), in which stimulation of acupoints located in pelvic limbs gave rise to gastric hypermotility, probably due to sensitization of the supraspinatus via the sciatic nerve, with a consequent vagal response.

The results observed through stimulation of sham points (T2) were compared with the negative control (T3), which did not receive any treatment. These results were concordant with the findings of Jobst (1986), who demonstrated that the meridians are stimulated only when the action is directed towards the exact point, since points away from the dermatomes do not conduct stimulation to adjacent nerve ends. This was also confirmed in a study conducted on dogs, in which use of lowfrequency electrostimulation at true points led to stomach contraction. This was not observed when the electrostimulation was done at false points at a distance from the true points (JOAQUIM et al., 2008).

Regarding stomach emptying among the rats that underwent electroacupuncture (T1), this took an average of $3 \mathrm{~h} 30 \mathrm{~min}$. However, Tabosa et al. (2004) demonstrated that $86 \%$ of the plastic spheres administered were expelled 90 minutes after electroacupuncture at the same points as used in the present study. Nonetheless, the differences relating to the type of sphere and use of anesthesia do not allow comparison between the results, since metal spheres were used in the present study, with anesthesia comprising an association between xylazine and ketamine, whereas Tabosa et al. (2004) used plastic spheres and physical immobilization. According to the literature, ketamine does not influence the 
gastrointestinal tract, but xylazine interferes with the motility of the gastrointestinal tract, thereby prolonging the duration of gastrointestinal transit (BUSTAMANTE; WERNER, 2009). Nevertheless, all the groups received the same anesthesia protocol, thus making the samples uniform, in the same way as in other studies that have examined stomach emptying in anesthetized animals (OUYANG et al., 2002; SUGAI et al., 2004).

From the results obtained, it is concluded that the animals that received electroacupuncture at the points BP6 and E36 presented significantly increased gastric peristalsis, thus diminishing the time taken for stomach emptying.

\section{References}

BALESTRINI, J. L.; TSUCHIDA, D.; FUKUDA, H.; PAPPAS, T. N.; TAKAHASHI, T. Acupuncture accelerates delayed gastrointestinal transit after abdominal surgery in conscious rats. Scandinavian Journal Gastroentorology, London, v. 40, n. 6, p. 734735, 2005.

BUSTAMANTE, H.; WERNER, M. Efecto sedativo de la asociación xilazina-morfina en caninos. Archivos de Medicina Veterinaria, Valdivia, v. 41, n. 3, p. 229-236, 2009.

CHOI, M. Ultrassonographic observation of intestinal motility of dogs after acupunctural stimulation on acupoints ST36 and BL27. Journal of Veterinary Sciencie, Seoul, v. 2, n. 3, p. 221-226, 2001.

DRAEHMPAEHL, D.; ZOHMANN, A. Acupuntura no cão e no gato: princípios básicos e prática científica. Editora Roca, 1997. 57 p.
JOAQUIM, J. G. F.; MORAES, R.; MIRANDA, J. R. A.; LUNA, S. P. L. Effect of acupuncture/electroacupuncture on gastric pressure and contraction of dogs measured by alternate current susceptometry and manometry (Canis familiaris). ARS Veteterinária, Jaboticabal, v. 24, n. 1, p. 9-14, 2008.

JOBST, K. Controlled trial of acupuncture for disabling breathlessness. Lancet, London, v. 328, n. 8521-8522, p. 1416-1419, 1986.

OUYANG, H.; YIN, J.; WANG, Z. P. J.; PASRICHA, P. J.; CHEN, J. D. Eletroacupuncture accelerates gastric emptying in association with changes in vagal activity. American Journal of Physiology Gastrointestinal and Liver Physiology, Bethesda, v. 282, n. 2, p. 390-396, 2002.

SUGAI, G. C.; FREIRE, A. de O. M.; TABOSA, A.; YAMAMURA, Y.; TUFIK, S.; MELO, L. E. Serotonin involvement in the eletroacupuncture and moxibustion induced gastric emptying in rats. Physiology and Behavior, Amsterdam, v. 82, n. 5, p. 855-861, 2004.

TABOSA, A.; YAMAMURA, Y.; FORNO, E. R.; MELO, L. E. A comparative study of the effects of eletroacupuncture and moxibustion in the gastrointestinal motility of the rat. Digestive Diseases and Sciencies New York, v. 49, n. 4, p. 602-610, 2004.

TAKAHASHI, T. Acupuncture for functional gastrointestinal disorders. Journal of Gastroenterology, Tokyo, v. 41, n. 5, p. 408-417, 2006.

TATEWAKI, M.; HARRIS, M.; UEMURA, K.; UENO, T.; HOSHINO, E.; SHIOTANI, A.; PAPPAS, T. N.; TAKAHASHI, T. Dual effects of acupuncture on gastric motility in conscious rats. American Journal of Physiology Regulatory Integrative Comparative Physiology, Bethesda, v. 285, n. 4, p. 862-872, 2003.

YIN, J.; CHEN, J. D. Z. Gastrointestinal motility disorders and acupuncture. Autonomic Neurosciences, Amsterdam, v. 157, n. 1-2, p. 31-37, 2010. 
